\title{
The role of the doctor: technician or statesman?
}

\author{
R F Stalley Department of Moral Philosophy, The University of Glasgow, Glasgow
}

\section{Editor's note}

In this paper Mr Stalley explores the role of the doctor through comparing and contrasting medicine and politics, but aims to illuminate the role of the physician rather than look at the nature of politics as many previous philosophers have done. $\mathrm{Mr}$ Stalley takes the extremes of the doctor as a 'philosopher king' and then as a 'technician' to illustrate the point that either one of these roles would seriously threaten the freedom of the individual to choose. The role of the doctor as an adviser, he feels, is much more what we want and need, as in that role he is more likely to combine scientific knowledge with the ability to achieve a sympathetic understanding of his fellow beings.

From very early times philosophers have made comparisons between medicine and politics or between the role of the physician and that of the politician or statesman. These comparisons have generally been intended to cast light on the nature of politics but in this paper I wish to consider whether they can also illuminate the role of the physician.

The philosophers who have compared medicine and politics have adopted widely divergent attitudes to the comparison. Plato, for example, seems to have believed that the two pursuits are precisely parallel to one another: in medicine we must bow to the authority of the expert physician and in politics to that of the wise statesman. ${ }^{1}$ Some modern philosophers, on the other hand, have assumed that medicine and politics are contrasting rather than parallel cases: we may submit to authority in medicine but must on no account do so in politics. ${ }^{2}$ I suspect that there are also many who would argue for a third position, that neither in politics nor in medicine should the individual give up his autonomy: in medicine ultimate authority must rest with the patient, in politics with the individual citizen.

I shall begin by considering two possible models for the role of the doctor in society. The first is that of the philosopher king. In his Republic, Plato suggests that in an ideal society all political power would be entrusted to rulers (usually known as 'guardians' or 'philosopher kings') who have undergone a long training in philosophy. They would have this authority because they alone have knowledge of the good and therefore know what are the right policies for the state and for the individuals within it. In developing this conception Plato several times compares his guardians to physicians or draws analogues between justice and health. ${ }^{3}$ I doubt if many members of the medical profession would explicitly claim this role of philosopher king, though no doubt there are those who in practice unconsciously usurp it. Nevertheless it is useful as a theoretical model with which to determine the relation between knowledge and authority. The other model I shall use is that of the technician or craftsman, about whom, as it happens, Plato also has a good deal to say. ${ }^{4}$ The essential point about the technician is that he is an expert on how to achieve predetermined goals but has no particular claim to decide which goals are worth achieving. $\mathrm{He}$ can thus be contrasted with the philosopher king who, because of his supposed knowledge of the good, does claim to be an expert on the ultimate ends which we should pursue.

\section{Doctors as philosopher kings}

The Platonic demand that all political power be entrusted to philosopher kings rests on the assumptions:

a) that there are correct solutions to the kinds of practical problem which concern politicians;

b) that a suitably trained individual can be relied on to discover the correct solutions.

The main reason for rejecting the ideal of the philosopher king is that political problems do not have definitively correct solutions. There can therefore be no experts in politics and so it makes sense to adopt a constitution which allows everyone a say in political matters and gives individuals the maximum freedom to determine their own ways of life. The same applies in medicine. If problems concerning health and sickness always had a correct solution and if doctors could be relied on to discover a solution it would make sense to give doctors absolute authority in these matters. But because such problems lack definitive answers the informed consent of the patient is essential.

One reason why practical problems may have no one correct solution is that we have to take account of a multiplicity of values. Plato thought that all human action aims at the good, so, whether we recognise it or not, there is one ultimate goal underlying everything we do. This seems to be a mistake. Each of us regards a variety of goals as worth 
pursuing for their own sake and most of us also recognise that we have obligations to do or refrain from a variety of different kinds of act. These beliefs as to what is ultimately worth pursuing and as to what is obligatory are our values. Even if we have a perfectly consistent set of values we may still experience value conflicts. For example a community may place a high value both on health and on education but limitations in its financial resources may force it to choose between building a hospital and building a school. There can be no cast-iron criterion for deciding such conflicts; either choice could be equally rational. Where a number of different individuals or of different groups have to make a joint decision the difficulties may be even greater because some may place a high value on things which others do not value at all. This multiplicity of values can affect medical decisions just as much as political ones. The goals characteristically pursued by medicine may conflict with other goals and need not be preferred to them. Explorers and missionaries for example, have quite rationally risked death and disease in the pursuit of what they regard as higher values. Even within the medical sphere there can be conflicts of value. If, for example, the treatment most likely to prolong life is painful or distressing a choice may have to be made between preserving life or enhancing its quality. The fact that medical techniques can be used for purposes such as contraception or cosmetic surgery which are not directly concerned with health only complicates matters further.

The second reason why practical problems lack definitive solutions is the indeterminacy of values. The point I have in mind here is that two people may agree in valuing such things as liberty, equality, health and education while differing quite radically in their conceptions of these things. For example, you may insist that a knowledge of literary classics is an essential part of being an educated man whereas I may claim that being educated is a matter of being well adapted to one's actual environment. In the last resort there may be no way of resolving disagreements of this kind. The same kind of thing can, I believe happen in medicine. Individuals and social groups obviously vary in their conceptions of health, their attitude to, and tolerance of pain and in their conceptions of what is a reasonable quality of life. The most notorious evidence for this is the fact that in spite of the increase in medical resources more people now regard themselves as ill; our conceptions of health and sickness have changed. Thus two people who both accept health as a goal can disagree about what this means and this disagreement may affect their practical decisions.

The third reason why practical problems may have no one correct solution is that they involve different attitudes to risk. Most practical decisions concern situations of uncertainty; we may not be sure exactly what the outcome of each possible choice will be and may be unable to quantaify precisely the likely advantages and disadvantages of each course. In such circumstances two ratio 1 men may favour quite different strategies; the cautious man will choose a strategy which minimises risks while the optimistic man will accept risks? In order to maximise his chances of achieving the most favoured outcome. Neither strategy can be provegd preferable to the other. This kind of disagreement can occur in medicine as much as in politics. For example some patients may choose a dangerøus operation to cure a painful condition while othe्fs may prefer to play safe and endure the pain.

It is easy to over-emphasise diversities and $\overrightarrow{d i s}-$ agreements in values. Cooperative activity of aty kind is possible only to the extent that individuols can work for common goals. In practice humin beings, particularly those brought up in the same culture, share many of their values and attitudes. Another important feature of humanity as we kn\&w it is the ability to achieve a sympathetic understanding of one another's values even when we not share them. This enables us to give one another advice, to engage in joint deliberation and to adopt common policies. If values were purely a matter individual whim or arbitrary choice then we wotPd be able only to shout at and coerce one another. Still the fact remains that however knowledgable or thoughtful an individual is, this knowledge or thoughtfulness cannot in itself give him the right determine other people's lives. The medical p fession cannot therefore claim the role of philosopher kings even where matters of health are concerneg. Whenever possible the ultimate decision must be left with the patients, just as in politics it must left with the individual citizens. We can thus sum up our discussion of the philosopher king model saying that it destroys the autonomy of the patiemt and does so largely because it is an erroneous account of knowledge.

\section{Doctors as technicians}

Put in its boldest and barest form the technician model suggests that it is the role of the doctor to inform his patient of the facts and then to carry out the patient's instructions. There is no call on the doctor to make any substantial decisions. The mo trouble with this, of course, is that it denies the responsibility we all have for our own acts. All $\Leftrightarrow$ us, even plumbers or carpenters, must be prepared to accept responsibility for what we do. F\&r plumbers and carpenters this may not be much of burden, because they are not usually concerned wi matters of great moral importance; they are not often asked to do something which might $\overrightarrow{\mathrm{B} e}$ morally wrong, and it is usually clear whose iostructions they are to follow. Things are not so easy for doctors; their acts, which may concesh matters of life and death, are of great moral 
importance; they may be asked to do things (eg abortions, euthanasia or AID) which are either immoral or of unclear ethical status; the patient may be obviously incapable of taking a decision or (even more difficult) it may not be clear whether he can take such responsibility; medical treatment may also affect other people besides the patient, for example his family, the medical staff who will be involved in treatment, the wider community which will pay for it or even an unborn fetus; so it may not be clear to whom exactly the doctor is responsible, or he may have to weigh up conflicting claims. For reasons such as these the work of doctors is bound to involve substantial moral decisions. These responsibilities cannot be evaded by appealing to higher authorities such as the law or professional ethical codes. Decisions of Parliament or of ethical panels must influence doctors but nobody, however august, can determine what is right or wrong; the ultimate responsibility still lies with the individual physician.

The technician model is based on the assumption that there is a clear distinction between setting the facts of the case before the patient and taking decisions on his behalf. This, too, seems highly dubious. Because information is complex, doctors will be obliged to be selective in what they tell their patients. Obviously it will not be possible to describe every conceivable treatment which could be given. Doctors will select what to say in the light of the treatment goals as they understand them; they will ignore courses which they regard as unethical, harmful, absurdly expensive or simply irrelevant to the patient's needs. The decision what to say to the patient thus depends on the ultimate values that are being pursued.

The language which the layman uses in discussing and thinking about health in relation to everyday life is full of evaluative and emotional overtones; one has only to think of words like 'pain', 'sickness' and 'death'. Even terms of medical origin acquire such overtones when they pass into common currency. Words such as 'cancer', 'leukaemia' and even 'operation' can carry a heavy emotional charge. The language of science on the whole avoids these overtones because it is concerned with what can be observed and measured precisely rather than with the interpretation of everyday experience, so there is a gap between ordinary language and the language of science. To use scientific results in conducting our everyday lives we have to be able to interpret them at the level of ordinary experience. This process of interpretation is not purely mechanical; it depends heavily on the values and background assumptions of the interpreter. For this reason a doctor who tried to copy the technical model could not avoid shaping his patients' attitudes by his choice of language. In practice, of course, doctors are fully aware of this and choose language which they believe will have the most salutory effect.
The attitudes of ordinary people to health and sickness are largely determined by those of the medical profession. For example mental conditions such as depression were not, I believe, regarded as illnesses until doctors began to treat them as such. So the attitude of the profession determines whether we see these as faults of character, to be overcome by personal effort, or as conditions for which we have no personal responsibility which are to be overcome by medical intervention. Similarly, professional attitudes may determine whether we accept some physical debilities as inevitable accompaniments of advancing age or resent them in the same way as we would disease or injury.

In one way there is a danger of overstating these points. Obviously doctors do not, and cannot be expected to go into moral agonies at every consultation. None of us could cope with life if we did not take certain values for granted. We have to evolve our own attitudes and operate with these more or less unconsciously. In doing this we are, of course, heavily influenced by the assumptions of the communities within which we live and of our various professions. The danger of the technician model is that it denies the existence of such valuepresuppositions and concentrates attention entirely on the doctor's factual knowledge. If we fail to recognise this we may invest the attitudes of the medical profession with the authority of science. This, I take it, is one of the main points behind Ivan Illich's attacks on modern medicine. ${ }^{5}$ A certain set of values becomes institutionalised within the medical establishment. Once this happens it becomes very difficult for those involved in medicine, whether as doctors or patients, to question these values and we lose the freedom to choose differently. In this way the technician model can be more threatening than the philosopher king, because it involves a concealed, rather than an open and explicit, domination, one which is the more difficult to evade because it is not exercised by any particular individuals.

\section{Doctors as advisers}

As patients we look to our doctors for advice. There are, of course, two kinds of advice. One kind involves giving a factual account of how a particular goal may be achieved. The other involves a positive recommendation as to what is or is not to be done. I think most of us would be disturbed if our doctors restricted themselves to the purely factual kind of advice; we expect also to receive recommendations; in other words we expect our doctors to play a positive role in decision-making. It is sometimes suggested that the doctor should do this because he is able to see the situation from a more detached, balanced and unemotional point of view, but I suspect most patients could find some other adviser who was equally balanced and unemotional and 
certainly less involved. So it is not the detachment or balanced attitude of the doctor that qualifies him to take an active part in decision making. What, I think, qualifies him for this role is his experience. Most patients who have to decide whether to undergo a course of treatment have no personal experience of the kinds of situation between which they are, in effect, choosing. Even if friends or relatives have suffered similar conditions in the past they will constitute a small and unreliable sample. So, however carefully the doctor describes the facts of what will happen, the patient may have very little idea of 'what it will really be like'. A doctor who has seen many patients in similar circumstances will, for that reason, be much better equipped to decide whether treatment is really worthwhile. So the question 'What would you do if you were in my position, doctor ?' is entirely appropriate.

Advice can be given only to the extent that human beings can share or, at least, enter sympathetically into one another's values. After all there is no reason why we should listen to recommendations based on a completely alien set of values. We prefer therefore, to look for advice to someone whose ultimate values are the same as our own but we can also seek advice from someone who does not share our values if he is able to understand and enter imaginatively into our goals. Ideally the help of an adviser will enable us to realise our own ultimate values more effectively than we could so by ourselves. So advice-giving depends on the capacity of human beings to understand one another, not in the way in which scientists understand natural phenomena, but by understanding what it is like to be in a person's position and being able temporarily to make his goals our goals.

In addition to looking to doctors for advice we also expect them to take decisions on our behalf. We do not expect even to be consulted on all the details of treatment. So our doctors exercise a delegated responsibility for us. The delegation of responsibility also depends on the capacity to share and understand one another's goals. (If we delegate responsibility to someone whose aims are completely different from our own then we are simply abandoning our own aims.) Thus when we seek the help of the medical profession we are relying on them, not simply as purveyors of factual information, but as human beings who are capable of understanding and working towards the ends which we ourselves value. We rely on the human understanding as much as on the technical knowledge of our doctors. The trouble with the philosopher king and technician models is that they both, in different ways, deny this point.

\section{Medicine and politics}

Thinkers of the past have often talked as though politics was exclusively concerned with relationships in which one party gives orders and the other passively obeys. In fact this is scarcely ever the cas Politics, in its widest sense, is concerned with conmunal action; it thus involved reconciling conflieting goals, giving advice and delegating decisions. These activities require the same virtues of humgn understanding which I have suggested are needgegd by doctors. They do not require the special knowledge of the philosopher king. So the analogy between medicine and politics is a good one, bat not for the reasons Plato supposed. The essent point is that both pursuits require not just scientific or factual knowledge nor any special expertise matters of value but the ability to achieve a sympathetic understanding of one's fellow beings.

These points have, I think, been recognised By the medical profession and by the wider public-witness that stock character of fiction, the wise ofd family doctor whose virtue is a deep understandiong of his fellow men, rather than a mastery of modern medical techniques. But there may well be a dang that factors such as shortage of time, increasing specialisation and the growth of medical technology may lead to the replacement of such medical statesmen by medical technologists - another stoek figure of fiction is the bright young doctor in the white coat. There are corresponding dangers politics. It is claimed that the growth of technology and the increasing complexity of the matters with which governments are concerned make it mose difficult for ordinary individuals to influence the political process. ${ }^{6}$ Plato, of course, did not envisage these developments but in one of his later works be says something which may serve us as an epilogue He contrasts free and slave doctors. The free doctors, in addition to being free men themselve्্⿸广 mostly have free men as patients; they take tiripe with them and try to educate them as to what they should do to be cured. The slave doctors are slaves themselves and treat mostly slaves; they rush around from patient to patient and issue ordess without attempting to explain the reasons. It would be exaggerated, but not absurd, to fear that tec. nology may make slaves of us all.

\section{References}

1Plato, Republic, 389b-c, 564b-c, 567c; Gorgias, 477? 480c; Statesman, 2936-300e.

${ }^{2}$ Wolff, R P (1970). In defense of anarchism. New Yor Harper and Row. p I5, cf. Flew, A G N (1973) Crime or disease ? London. Macmillan, p I8; Kennyo A J P (1969) Mental health in Plato's Republio, Proceedings of the British Academy LV, p 250.

${ }^{8}$ Republic, 389b-c; 444d-445a; 564b-c; 567c.

Republic, 332b-334b, 340c-35od.

'Illich, I (1976). Limits to medicine. London. Maricin Boyers.

'Wolf, R P. In defense of anarchism, pp 17, 70-1.

'Plato, Laws, 720a-d. 